\section{Mixed Income Housing (MIH)}

Claudia Trillo

University of Salford, Salford, UK

\section{Synonyms}

Mixed-income neighborhoods; Neighborhood restructuring; Neighborhood revitalization; Urban regeneration; Urban renewal

\section{Definition}

Mixed Income Housing (MIH) is the outcome of a deliberate effort to build a mixed-income development, usually including a variety of housing typologies, sometime combined with the goal of creating a mixed-tenure development. International consensus on a more specific definition of MIH does not exist; instead, multiple expressions can be equally used, with similar meaning. The expression MIH is mainly used within the USA context where it is sometime replaced by mixedincome neighborhood. In Europe, MIH tend to fall within initiatives on (sustainable) urban regeneration, neighborhood restructuring, urban renewal, while the UK legislation often refers to "pepper-potting" with respect to different tenures in the same neighborhood aimed to achieve MIH. Non-English-speaking countries tend to use different terms.
The MIH policies are challenged by a specific connotation, i.e., in the United States it is the combination between urban poverty and black or Latinos ghettoes; hence, spatial segregation is combined with racial considerations which are less present in other countries, except for South Africa. In the USA, desegregation in public housing estates became a legal obligation following the famous 1969 Gautreaux case, because of the application of the 1964 Civil Rights Act prohibiting racial discrimination in federally funded activities.

\section{Mixed Income Housing and Inclusive Cities}

\section{Introduction}

According to Brophy and Smith (1997: 4), "mixed-income housing means a deliberate effort to construct and/or own a multifamily development that has the mixing of income groups as a fundamental part of its financial and operating plans. The ratio of income levels and the developer's reasons for seeking to create a mixedincome development will vary. In general, however, a mix of incomes is planned because of the juncture of community desire and need, housing market conditions in the surrounding area, and the availability of financing and/or subsidies." According to Schwartz and Tajbakhsh (1997), MIH nature depends on a variety of factors, including the percentage of low-income 
households, the quality of housing in terms of size and amenities, the sponsors - public, nonprofit, for-profit organizations, homeowners, and renters. Depending on the mechanisms for achieving $\mathrm{MIH}$, these are mainly divided in two groups, vouchers and inclusionary housing policies.

As highlighted by the editors of a special issue of CityScape on "Mixed Messages on Mixed incomes" (Fraser et al. 2013: 7): "During the past several decades, a number of housing programs sought to create mixed-income housing and neighbourhoods in the United States and Europe to negate the effects of concentrated poverty. In the United States, such initiatives have included the U.S. Department of Housing and Urban Development's Moving to Opportunity housing experiment, whereby low-income residents volunteered for relocation to low-poverty areas; the Housing Opportunities for People Everywhere (HOPE VI) Program for public housing transformation; and Choice Neighbourhoods, a program broadly based on the HOPE VI model but expanded to revitalize entire neighbourhoods. In Europe, such initiatives fall under the rubric of neighbourhood restructuring or urban renewal. These efforts often include mixed-housing strategies and have been implemented in the Netherlands, the United Kingdom, Germany, France, Finland, and Sweden. European strategies focus more on mixing homeowners with social renters the equivalent of public housing renters in the United States - with the similar assumption that a more diverse socioeconomic mix of residents will remove the negative neighbourhood effects of poverty. By far the largest European mixedhousing initiative is the Right to Buy (RTB) scheme in the United Kingdom, mainly aimed at ensuring different tenures (pepper potting) and as a consequence more diversity. Since the 1970s, more than 2.7 million socially rented houses have been sold with large discounts, mainly to existing tenants and other more affluent households." Example from countries less investigated within the English-language literature but equally innovative, include MIH examples undertaken in France, Italy, and in Spain with the 1990s integrated regeneration programs (Aguirre 2018; Trillo 2009, 2015; Calavita and Mallach 2010).

\section{Mixed Income Housing: A Historical Overview}

Mixed Income Housing has quite a long tradition within the European planning theories and practices. The garden city paradigm, as developed by Sir Ebenezer Howard, included great consideration for a balanced social-mix, although as Fishman (1977) noted, the working-class families laboring in Letchworth - one of the first garden cities built by the company founded by Howard - did not manage to afford living in the city, hence, the social-mix was more an aspiration than an achievement. However, a real and proper systematic attempt to pursue explicitly mixed-income housing policies started to emerge in the 1990s, following the criticisms raised by the large public estates built in the 1960s and 1970s and mainly addressed to the low-income class. This took the form of public policies on urban renewal focused on council housing transformation in the UK (Levy et al. 2010; Bond et al. 2010), plans for improving public housing estates both in Italy - Piani di recupero urbano following the National Law 493/1993 - and in France -Loi d'Orientation pour la Ville 1991 and Loi Solidarité et Renouvellement Urbain 2000 - and more generally, various initiatives differently labelled as neighborhood restructuring, urban renewal, neighborhood revitalization, neighborhood renewal, and council-housing transformation. It is only partly true that a European way of delivering housing policies and urban regeneration cannot be clearly identified. In facts, despite a lack of explicit mandate on spatial and housing policies, the European Union did profoundly influence urban policies delivered by member states and steered urban regeneration and renewal initiatives towards a common, integrated, and sustainable way (see for example Hess and Cycak 2018). The European Commission developed a consistent conceptual framework aimed at underpinning social inclusion within urban regeneration instruments and tools, as clearly emerges from a plethora of documents such as: the 1998 Communication from the Commission to the Council, the European Parliament, the Economic and Social Committee and the Committee of the Regions "Sustainable Urban Development in the European Union: a Framework for Action". The three Community Initiatives Urban 1, Urban 2, and Urban + provided all member states with a clear mix of funds 
both for infrastructure and for social initiatives, explicitly aimed at talking three main challenges: (1) reinforcing the competitiveness of Europe's towns and cities; (2) tackling social exclusion, improving access to jobs and training for all, including immigrants and those from ethnic minorities, building the capacity of local communities to help themselves; (3) supporting physical and environmental regeneration, ensuring sustainability and improving the attractiveness of towns and cities, building on the cultural and architectural heritage of urban areas. This effort allowed developing a consistent set of examples throughout all the member states, featured by common features such as integrated approach between competitiveness and social exclusion: social, physical and environmental regeneration. Starting from the assumption that social exclusion is a cost for society as a whole and a drain on urban economic development (EC 1998), the European way to approaching social exclusion clearly posited anti-poverty urban strategies within an integrated and comprehensive approach, in which social-mix was one of the elements of socioeconomic inclusion in cities. For this reason, finding specific initiatives aimed at achieving MIH can be challenging, since this goal is blurred within a wider urban regeneration strategy.

In the USA, the concept of social-mix as a key ingredient of the good city was masterfully depicted by Jane Jacobs in 1961. However, it is the concept of "neighborhood effect" as developed by the Chicago sociologist Wilson (1987) that showed the detrimental effects of segregation for minorities in urban ghettos, as their inhabitants were deprived of a safe environment and good schools and access to job. In terms of programs, HOPE IV is the most important neighborhood revitalization program in the USA. Launched in the early 1990 s, it largely draws from the theoretical basis of New Urbanism, a USA movement which started in the 1980s and was codified in 1993 in the form of a Charter by a group of forward-thinking architects and planners. The social-mix and integrated development, achieved through a proper blend of functions (mixed-use) wisely concentrated around public transit nodes (the transit-oriented development concept), recalls the Garden City principles and the idea of a balanced community as blueprint for sustainable urban development. Unfortunately, many of the low-income people who were evicted from their public housing to make room for the mixed-income neighborhoods were never able to return because the number of low-income housing units was reduced.

\section{Implementing Mixed Income Housing Strategies}

Although instruments and tools aimed at implementing MIH strategies are highly dependent on the specific normative, financial, and geographic context, still it is possible to broadly identify two main groups based on their reliance on a specific urban development initiative.

The first group of instruments and tools is disjointed by any specific urban development process and is mainly based on the rationale of directly subsidizing people, i.e., low-income and very low-income residents and supporting them to access properties which would be unaffordable to them. This would allow them to access neighborhoods, which should be theoretically chosen freely, including affluent communities. One example of this first group is provided by the vouchers policy applied in the USA. Although vouchers are not area based and are mainly aimed at supporting low-income groups to afford a home where the market prices would be not affordable to them. In many cases, however, landlords refuse to rent to them in middle- or high-income areas, and lowincome families end up in low-income neighborhoods anyway.

The second group of instruments and tools are displayed as part of a wider spatially focused strategy, i.e., they are incorporated within urban development or urban regeneration initiatives. From a land economics perspective, they are based on the rationale of recapturing for public benefit that part of the increment in land value, which stems from public initiative (area betterments, construction of public infrastructures, granting planning permission) and is not directly related to the private developers' entrepreneurial initiative.

While under different contexts the economic rationale remains the same, its normative translation into instruments and tools varies enormously (Trillo 2009). In Europe, it varies 
according not only to the different national context but also to the regional one, depending on the devolution of powers in the land use field. In Spain, for example, at national level, land value recapture is applied within the framework of the perecuacion, which is firmly rooted in the Constitution, and tailored to the regional-specific contexts through different regional land-use laws. Among other public benefits that developers are expected to give back to the local authorities, Vivienda protegida, i.e., affordable housing, is included. A percentage of affordable housing shall be included in any new development, thus making them accessible to people of different income. In Italy, the same mechanism is known as perequazione, also applied to produce affordable housing as part of the standards required by law as public contribution in any new development. Affordable housing provision may be complemented with provision of public spaces and infrastructure according to the local plans (see for example, Janssen-Jansen et al. 2008; Trillo 2015). In the UK, the rationale of giving back the land value depending on public initiatives and not on private entrepreneurial effort is enabled by the so-called Section 106. In the USA, inclusionary housing policies require developers to provide a certain percentage of affordable housing integrated with market housing, thus allowing low-income and/or very low-income residents to access neighborhoods which would not be financially accessible otherwise. However, land value recapture is also pursued with different instruments, such as Public Benefits Zoning, Community Benefits Strategy, and Public Benefit Bonus. Land Value Recapture aimed at producing affordable housing has been applied in Latin America, specifically in Brazil and Colombia. Their application in contexts challenged by high level of poverty and inequality has been criticized, since overreliance on the private initiatives to achieve public goals has led to inconsistent results (Freire Santoro 2019).

\section{Mixed Income Housing: Useful, Useless, Counterproductive}

No consensus emerges from the literature on the actual impacts of Mixed Income Housing on achieving inclusive cities, with MIH having been considered either useful or useless, or even counterproductive. The reasons for such a contradiction within the scholarship are mainly ideological. First, MIH is still a politically biased topic, reflecting either a socialist or a neo-liberal approach to social integration. As such, on the two extremes, MIH policies have been implemented either based on ethical concerns or for reducing the risk of investment in deprived and red-lined areas that social mix should make more desirable. It is worth reminding that red-lining was a common practice used by all US government levels to exclude some areas from granting mortgages, because of the risks associated with the unstable property values due to social stigma, physical decay, and high crime rates ghettoes. This practice has perpetuated a de facto spatial, social, and racial segregation in USA cities, which is still far from being overcome after having been promoted by public policies for years (Rothstein 2017). Kearns et al. (2013: 48) define the rationale of building an ethical argument for justifying public housing policies as orthodoxy and discuss how the promotion and development of mixed-tenure communities in Europe are a kind of orthodoxy for planners and housing policy makers.

The concept of social mix is deeply intertwined with the aspiration to achieving sustainable communities, hence because mixed-tenure is considered a means to integrate different social groups from different incomes, then sustainable urban development and regeneration initiatives usually include mixed-tenure, mixed-income, and mixedhousing types measures (though according to Berube 2005 little evidence support this hypothesis). With respect to social integration as hypothetically fostered by mixed-tenure, Kerns et al. (2013: 49) contest that the association between $\mathrm{MIH}$ and social mix is weak (Musterd and Andersoon 2005: 26) and the positive interaction across different social groups can be challenged by great either social or income gaps.

Kearns et al. (2013) discussed a wide body of literature evidencing a weak or nonexistent correlation between expected positive impact and mixed-tenure, then gathered informed opinions from several experts and practitioners, 
highlighting a variety of issues happening in the implementation phase, even contradicting the original goals. Indeed, assessing whether failures depend either on the planned measures or on their implementation is a common evaluative issue. Moreover, very few studies take in consideration all the correlated variables which might have an impact on the success of MIH policies, such as connection to public transport; geographical scale of the initiative within the wider regional context; scale of the initiative within the regional labor market; combination of MIH local initiatives with national, regional, and other local initiatives aimed at supporting better education of weaker population, including schools; combination of MIH with better delivery of public services, including health services and childcare; capital investments on public spaces. The reality is, as highlighted by Galster (2012), that still many questions remain unanswered concerning $\mathrm{MIH}$, such as the extent of the concentration, the geographical limits of the study area, and the scales for integration. With these basic knowledge gaps, it is hard to assess the real success of area- based initiative, even more difficult the success of geographically neutral initiatives. For example, USA programs such as Gautreaux, Vouchering Out, Moving to Opportunity programs have been assessed by a vast body of both academic and nonacademic literature seeking to ascertain the correlation between improved life-chances and spatial relocation (Atkinson 2005).

Two relevant positive points regarding $\mathrm{MIH}$ are that neither they pose concerns to residents, who do not appear to be interested in the mixed nature or their estates (Jupp 1999: 10) and can be "described as 'agnostic' about their neighbourhoods" (Bailey and Manzi 2008: 4), nor MIH seem to have a significant impact on real estate market values of surrounding areas, apart from specific international contexts plagued by legacy from racist history, where MIH combines integration of social groups both from different level of income and from different racial backgrounds and have a very moderate impact on the real estate values of surrounding areas. A recent study conducted in Santa Monica, USA (Nzau and Trillo 2019), showed how a standard percentage of housing for low-income and very low-income residents within affluent neighborhoods is not perceived as detrimental to the community by residents.

\section{Assessing the Impact of MIH Policies}

In the last decade international groups of experts, think tanks, and dedicated focus groups shed light on the state of the art of the evaluation of MIH outcomes mainly in the USA and UK, partly in Europe with a prevalence of studies on the Netherlands. According to Bolt et al. (2010), the outcomes from policies seeking to achieve desegregation and social mix seldom meet the expected targets. They argued that not only outcomes did not meet expectations, but even that unintended negative outcomes were achieved. For example, when social groups move, they experienced severe difficulties in establishing new social ties in nonhomogeneous social environments. This effect has been discussed on a variety of case studies, by adopting the concept of social capital as suggested by Putnam (2000), and by assessing different types of ties generated within the social network, either in the form of bonding or bridging. It is worth reminding that according to Putnam, the social glue that nurtures a healthy community mainly stems from a network of ties linking together the residents. Those links are either internal to the community and act as social glue activating relationship inside the neighborhood (bonding) or enabling connections between community members and externals (bridging).

Bolt et al. (2010: 132) gathered a plethora of research covering cases from both side of the Atlantic Ocean drawing as conclusion "that there is a huge gap between ambitious policy rhetoric and the limited policy effect on residential segregation." They achieve this conclusion by focusing on how spatial desegregation has contributed to social mobility for poor and minority ethnic groups, with an emphasis on USA and Northern European examples, showing how MIH have in some cases led to exclusionary processes within the housing market. This has happened not only in USA HOPE IV cases but also in Sweden and Belgium, where social mixing has been used to cover hidden policies of denying housing to minorities in ethnically concentrated 
neighborhoods. Generally, an unintended consequence of urban renewal policies has been the reduction of housing opportunities for less affluent minorities that is happening throughout the entire Northern American and European regions (UN Habitat 2016). Unfortunately, this phenomenon is worsened by a drastic reduction of public support to affordable housing that is happening almost in any European country, following the 1980s neoliberal shift of housing policies pioneered by the UK Right to Buy Thatcher program.

A different assumption on the rationale supporting an argument in favor of MIH stems from an ethically concerned planning theory and practice. MIH can be combined with a variety of other policy actions to achieve social inclusion, in alignment with the targets set by the United Nations Sustainable Development Goal 11. The two steps targeted in 2020 (substantially increasing the number of cities adopting and implementing integrated policies and plans towards inclusion) and in 2030 (enhancing inclusive and sustainable urbanization) do require adoption of spatial desegregation measures, and so far, very little alternative policies exist beside MIH. As reinforced by Bailey et al. (2006: 22), "The desire to achieve mixed communities should not be seen as an end in itself but as one important precondition for achieving successful and sustainable places to live. These residential environments should not only be well designed and well managed, but also provide access to the full range of high-quality services including leisure and employment opportunities." The Joseph Rowntree Foundation have supported a variety of studies on $\mathrm{MIH}$, including the Berube (2005) comparative study (USA and UK) of MIH demonstrating that the reduction of Wilson (1987) "neighborhood effect" of mono-tenure estates is an important goal (Bailey et al. 2006: 92).

A recent attempt to promote a discussion on the current state of the art on MIH has been pursued by a group of experts under the umbrella of the Urban Affairs Association, more specifically during two annual conferences (2011 and 2012) culminated in a symposium generating a special issue for CityScape (2013), the journal published by the USA Department of Housing and Urban Development
Office of Policy Development and Research. This issue, significantly entitled "Mixed Messages on Mixed Incomes," depicts an international position still uncertain about the effectiveness of MIH. The editors clearly reinforce that MIH policies reemerged in the early 1990 s were a response to the dramatic conditions of hyper segregated poverty. This was well illustrated in the works of scholars such as Massey and Denton (1993) and Wilson (1987). The latter has made a point that spatially concentrated poverty, the so-called ghettoization, fosters the negative performances of the poor (the neighborhood effect). However, MIH have gone far beyond the regeneration of largescale blighted and segregated public housing, grasping the attention of a variety of decisionmakers, from both the public and the private sector. Some, however, have noted a misused belief that producing community benefits through MIH can justify justifying speculative real estate initiatives by legitimating public-private initiatives that turned to be gentrification operations (Dutton 2007; Lees 2008; Rose et al. 2013; Skirtz 2012, all cited by Fraser et al. 2013: 3).

In general, there is a scarcity of English language literature covering case studies from geographical context of non-English-speaking countries on MIH. However, a large body of mainly nonacademic literature exists both on the Northern and Southern European Union member states. This is mainly due to the support that European Commission ensured to the integrated urban regeneration initiatives supported by structural funds in accordance to the sustainable urban development common goals as elaborated in a variety of European Commission documents (Trillo 2016, 2017). A qualitative analysis of the outcomes of two case studies corresponding to two neighborhoods of a Southern European city where Roma population have been integrated (Trillo 2016) showed different patterns, one unsuccessful and another successful. Yet the ethnic group to be integrated is the same (Roma) and the two case studies have been selected in the same geographical context (Reggio Calabria, a Southern European peripheral medium size city). What differs in the two case studies is the physical shape of the two neighborhoods (one poorly connected though public transport and lacking 
good quality services and public spaces) and the percentage of "pepper potting."

The lack of evidence on measurable impacts from MIH might be affected by the theoretical and methodological difficulties associated with the measurement of social and cultural impacts from regeneration. This is a topic broadly studied in the disciplinary field of the evaluative studies. Consensus exists on the issue that theoretical and methodological gaps plaguing the assessment of social complex values often lead to underestimate the impact of relevant interventions on the built environment, as well as, of policies and programs. Not being able to correctly assess the positive impact of MIH should not lead to the conclusion that such an impact does not exist. Furthermore, while the economic and physical impacts of MIH can be assessed in the short and medium term, indepth and durable social impacts are expected to span across a couple of generations, since it is unlikely that a drastic social change might happen in a low-income social group whose social ties are already in place and socioeconomic dynamics already consolidated. It is reasonable to expect that socioeconomic impacts from MIH policies implemented in the 1990s are evident only now.

Other unintended consequences of $\mathrm{MIH}$ are mainly associated with vested intent to move away not desired social groups in order to increase property values and, generally, with gentrification. However, a reasonable increase in the property value indicates that policies are working and places are becoming more desirable, and MIH may be helpful to reduce displacement and rapid change of the local identity. Local community character preservation is a key element of sustainability, as suggested by the SDG11, which emphasize sociocultural values of sustainable communities.

Participatory and community-based implementation is paramount with this respect since the local identity is expected to dynamically evolve in a positive way but not to be overwhelmed by exogenous forces holding stronger economic power. The nature of MIH is enabling interaction across different social groups holding nonsymmetric powers and it is evident that achieving a socially balanced mix just by mixing people in the same place may lead to unintended negative consequences. Nevertheless, MIH policies complemented by consistent social integration policies may significantly contribute to the achievement of some targets set by the United Nations within the Sustainable Development Goal 11.

\section{Cross-References}

Housing Policies

\section{References}

Aguirre Such J (2018) Inclusión social, vivienda, regeneración urbana... los temas de las Buenas Prácticas en España, URBACT, 21st March. http://urbact.eu/inclusión-socialvivienda-regeneración-urbana. . .-los-temas-de-las-buenasprácticas-en-españa

Atkinson R (2005) Neighbourhoods and the impacts of social mix: crime, tenure diversification and assisted mobility, CNR paper 29. ESRC Centre for Neighbourhood Research, Glasgow

Bailey N, Manzi T (2008) Developing and sustaining mixed tenure housing developments Joseph Rowntree Foundation, Round-up, Reviewing the evidence, www. jrf.org.uk

Bailey N, Haworth A, Manzi T, Paranagamage P, Roberts M (2006) Creating and sustaining mixed tenure housing developments. Published for the Joseph Rowntree Foundation by the Chartered Institute of Housing. www.jrf.org.uk

Berube A (2005) Mixed communities in England: a US perspective on evidence and policy prospects. Joseph Rowntree Foundation, York. www.jrf.org.uk

Bolt G, Phillips D, Van Kempen R (2010) Housing policy, (De)segregation and social mixing: an international perspective. Hous Stud 25(2):129-135

Bond L, Sautkina E, Kearns A (2010) Mixed messages about mixed tenure: do reviews tell the real story? Hous Stud. iFirst article, 1-26, October 2010

Brophy PC, Smith RN (1997) Mixed-income housing: factors for success. Cityscape: J Policy Dev Res 3 (2):3-31

Calavita N, Mallach A (eds) (2010) Inclusionary housing in international perspective. Affordable housing, social inclusion and land value recapture. Lincoln Institute of Land Policy, Cambridge

De Salvo JS (1974) Neighbourhood upgrading effects of middle- income housing projects in new York City. J Urban Econ 1(3):269-277

EC (2003) Partnership with the cities. The URBAN community initiative, European Union Regional Policy. http://ec.europa.eu/regional_policy/sources/docgener/pre senta/cities/cities_en.pdf 
Fishman R (1977) Urban utopias in the twentieth century. Basic Books, New York

Fraser J, Oakley D, Levy D (eds) (2013) Special issue of city scape, "Mixed Messages on Mixed incomes" vol 15, no 2, U.S. Department of Housing and Urban Development Office of Policy Development and Research. http:// www. huduser.org/periodicals/cityscape.html

Freire Santoro P (2019) Inclusionary housing policies in Latin America: São Paulo, Brazil in dialog with Bogotá, Colombia, Paper draft for discussion on NYU 02-25-2019

Galster GC (2012) Neighbourhood social mix: theory, evidence, and implications for policy and planning. Paper presented at the 2009 international workshop at Technion University: "Planning for/with People"

Jacobs J (1961) The death and life of great American cities. Vintage, New York

Janssen-Jansen L, Spaans M, Van der Veen M (2008) New instruments in spatial planning: an international perspective on non-financial planning. IOS Press, Amsterdam

Jupp B (1999) Living together: community life on mixed tenure estates. Demos, London

Kearns A, McKee M, Sautkina E, Weeks G, Bond L (2013) Mixed-tenure orthodoxy: practitioner reflections on policy effects. Cityscape: J Policy Dev Res 15(2): 47-67

Lees L (2008) Gentrification and social mixing: towards an inclusive urban renaissance? Urban Stud 45(12): 2449-2470

Levy DK, McDade Z, Dumlao K (2010) Effects from living in mixed-income communities for low-income families. Metropolitan Housing and Community Center, Urban Institute

Massey D, Denton N (1993) The continuing case of segregation: American apartheid: segregation and the making of an underclass. Harvard University Press, Cambridge

Musterd S, Andersoon R (2005) Housing mix, social mix, and social opportunities. Urban Aff Rev 40(6):761-790

Nzau B, Trillo C (2019) Coping with gentrification in growing cities. Insights from an inclusionary housing program in the Los Angeles area. Hous Stud. Under review

Putnam RD (2000) Bowling alone: the collapse and revival of American community. Simon and Schuster, New York

Rothstein R (2017) The colour of law. A forgotten history of how our government segregated America. Liveright, New York

Sautkina E, Bond L, Kearns A (2012) Mixed evidence on mixed tenure effects: findings from a systematic review of UK studies, 1995-2009. Hous Stud 27(6):748-782

Schwartz A, Tajbakhsh K (1997) Mixed-income housing: unanswered questions. City 3(2):71-92

Trillo C (ed) (2009) Transfer development rights and Urban Design. Alinea, Florence

Trillo C (2015) Non-financial compensation, social housing and urban design quality: beyond "perequazione". Eur Plan Stud 23(8):1627-1645

Trillo C (2016/2017) Quality of urban design and sustainable urban development: success and failures in fighting social exclusion. Int $\mathbf{J}$ Sustain Dev Plan 12 (4):829-838

Trillo C (2017) International property market- driven regeneration: a challenge to sustainable urban development? J Urban Regen Renewal 10(4):1-10

Werner Hess H, Cycak W (2018) The European Union and urban development: a dossier, www.bod.de Books on Demand

Wilson WJ (1987) The truly disadvantaged. The inner city, the underclass, and public policy. The University of Chicago Press, Chicago 